\title{
First detection of the "flowerpot snake" Indotyphlops braminus (Daudin, I 803) (Serpentes Typhlopidae) in Ischia (Italy): a new possible invasive species
}

\author{
Giovanni Paolino', Raffaella Scotti \& Mauro Grano ${ }^{3 *}$ \\ ${ }^{1}$ La Sapienza University of Rome, Piazzale Aldo Moro, 5, 00185 Rome, Italy; email: gio8519@gmail.com \\ ${ }^{2}$ Via Quercia 10, 8077 Ischia, Italy; email: raffischia@libero.it \\ ${ }^{3}$ Sezione Lazio of Societas Herpetologica Italica, Via Valcenischia 24, 00141 Rome, Italy \\ *Corresponding author, email: elaphe58@yahoo.it
}

ABSTRACT

\begin{abstract}
Indotyphlops braminus (Daudin, 1803) (Serpentes Typhlopidae), also known as "flowerpot snake", is a small subterranean blind snake, which holds the widest distribution on the globe. This species, by taking usually refuge in pot plants, has been indirectly transported by humans via the main trade routes. Close to Europe, I. braminus has been reported in Macronesia (Canary Islands and Madeira) and Northern Africa; while in Europe it has been detected in the Balearic Islands (specifically in Mallorca) and one population was also found in the Province of Almería, in the southern Iberian peninsula. Up to date, no further reports were made in Europe. With this note, we report the first Italian observation of I. braminus, specifically in Ischia Island. As for other alien species, an early detection of allochthonous populations plays a pivotal role to activate specific and useful management strategies.
\end{abstract}

KEY WORDS

Allochthonous; flowerpot snake; Indotyphlops braminus; Ischia; Italy.

Received 20.10.2019; accepted 03.11.2019; published online 19.11.2019

\section{INTRODUCTION}

Introduction and spread of alien species are considered one of the main threats to biodiversity at different scales. Indeed, this is mainly due to the rates at which specific species are introduced, as well as their possible destructive impact on native biota (Rato et al., 2015). In this spectrum, reptiles are usually involved both as alien invaders and as native sufferers (Rato et al., 2015). Accordingly, an early detection of allochthonous populations plays a pivotal role to activate specific and useful management strategies (Rato et al., 2015).

Indotyphlops braminus (Daudin, 1803) (Ser- pentes Typhlopidae) is a small subterranean blind snake, originating from Indo-Malayan region, showing a length ranging between $120 \mathrm{~mm}$ and 230 $\mathrm{mm}$ (Bamford \& Prendergast, 2017). Twenty rows of scales around the body and 292-368 transverse rows characterize the body scales in this species (Figs. 1,2). In order to burrow in the soil, the rostral plate and the two nasal plates protrude from the mouth to form a sort of rounded shovel (Geniez, 2018). The nasal plate is divided by a furrow, which is directly in contact with the pre-ocular scale (Geniez, 2018) while the head shows typical rows of whitish cephalic glands (Fig. 3) (Wallach, 2009). An obtuse, conical spine characterizes the terminal caudal vertebra, distinguishing the tail from the rest 
of the snake's body (Fig. 4) (Bamford \& Prendergast, 2017).

Indotyphlops braminus is mainly fossorial and rarely comes to the surface. When it rains and the soil becomes humid and waterlogged, the snake finds it easier to move across the surface to find food or new sites to colonize (Bamford \& Prendergast, 2017). The diet is mainly characterized by ants and termites (including larvae and pupae), beetle larvae, small flies, fungi and even insect excrement (Bamford \& Prendergast, 2017).

As reported above this snake is restricted to warm areas with high humidity, usually in the tropics. However, I. braminus, among the snakes, holds the widest distribution on the globe (Rato et al., 2015; Bamford \& Prendergast, 2017). Indeed, this species, by taking refuge in pot plants (from which it takes the name of "flowerpot snake"), is indirectly transported by humans via the main trade routes (Bamford \& Prendergast, 2017). Furthermore, its parthenogenic reproduction increases its worldwide distribution, allowing the colonization of several sites in Asia, Oceania, Africa and Americas (Rato et al., 2015; Kamosawa \& Ota, 1996).

Close to Europe, I. braminus has been reported in Macronesia (Canary Islands and Madeira) and Northern Africa, while in Europe it has been detected in the Balearic Islands (specifically in Mallorca) and one population was also found was found in the Province of Almería, in the southern Iberian peninsula (Zamora, 2017). To our knowledge, to date, no further reports were made in Europe.

\section{MATERIAL AND METHODS}

Ischia is a volcanic and mountainous island in the Tyrrhenian Sea that lies at the northern end of the Gulf of Naples, about 30 kilometers from the city of Naples. As in the main Spanish sites (Balearic Islands and Southern Iberic peninsula), Ischia's climate is Mediterranean with dry summers and mild wet winters, further justifying the survival of this snake in the little Italian island.

The site where our observations were made is a private suburban garden at $40^{\circ} 44.3130^{\prime} \mathrm{N}$ $13^{\circ} 56.9060^{\prime} \mathrm{E}, 67.3$ meters above sea level and about 100 meters from the sea. The site is characterized by lava soil, gardening plants and grass, while the surrounding area by Mediterranean scrub and pine trees (Pinus pinaster Aiton and Pinus halepensis Miller).

\section{RESULTS}

\section{Systematics}

Classis REPTILIA Laurenti, 1768

Ordo SQUAMATA Oppel, 1811

Subordo SERPENTES Linnaeus, 1758

Familia TYPHLOPIDAE Merrem, 1820

Genus Indotyphlops Hedges, Marion, Lipp, Marin et Vidal, 2014

Indotyphlops braminus (Daudin, 1803)

The first observation in this area dates back to 24 months ago, with a mean observation of 15 specimens per month and an increase of observations during the rainy days and summer season (June-September). According to what reported above, if it is true that that the dispersal capacity of this snake is limited (because of its reduced mobility and underground customs, which require loose soils for gallery burrowing), at the same time, its adaptability to lava soil remains interesting in Ischia island as well as in Macronesian islands.

Finally, as in the main Spanish populations (including Canary Islands), the proximity of the site of our observation to the sea, stress the fact that the high humidity and temperature stability create an ideal habitat for the survival and reproduction of this species (Zamora, 2017).

\section{DISCUSSION AND CONCLUSIONS}

Concluding, as far as we know, this is the highest latitude in which a population of this species has been found and this is the first observation of $I$. braminus in Italy. Based on its small size, on its elusiveness, fossil ecology and diet, the ecological and economic impact of this species in the native biota is not yet known.

At the same time, the evaluation of a possible impact on the native arthropod communities, with a relative involvement in the entire trophic chain, 


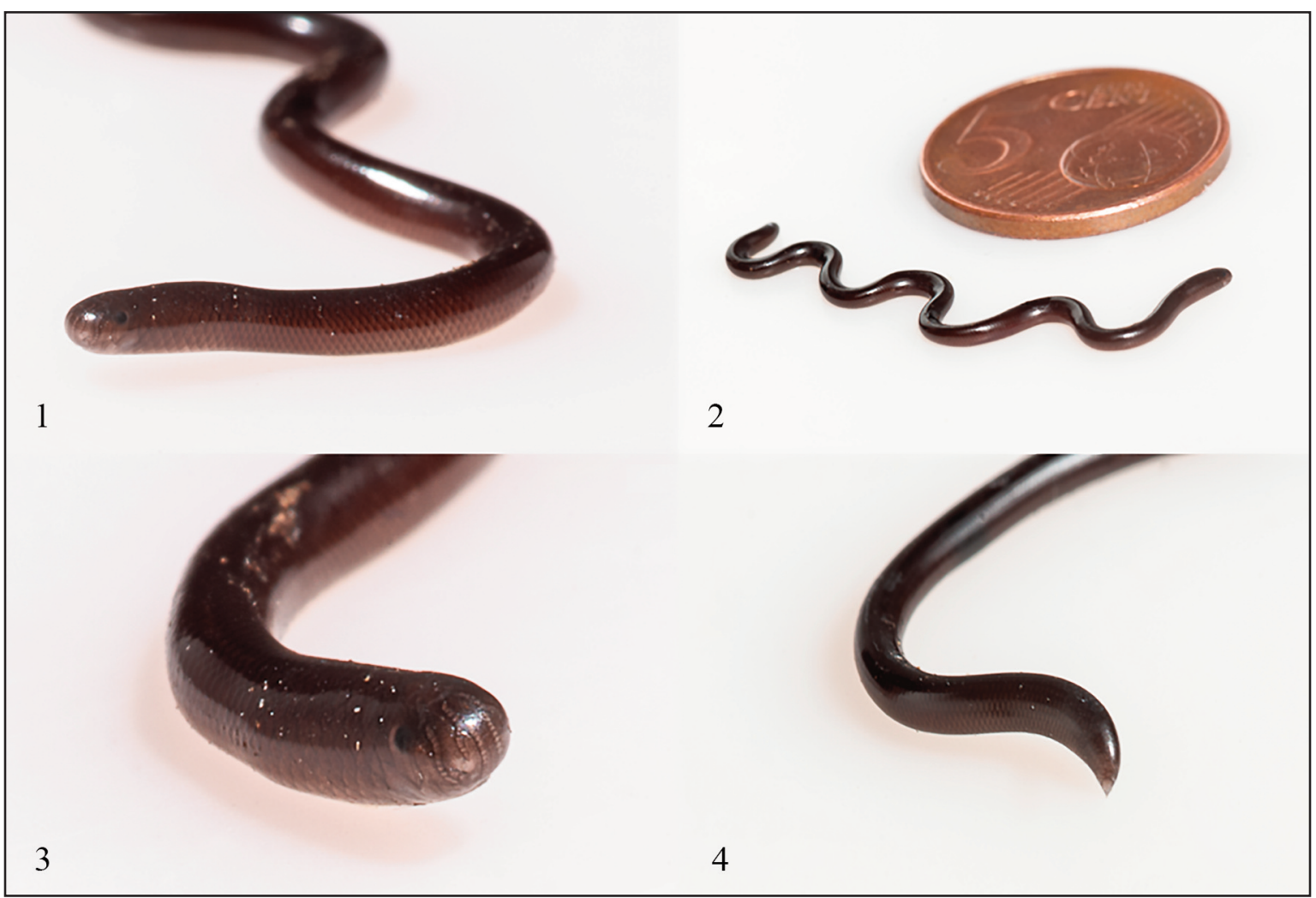

Figures 1-4. Indotyphlops braminus. Fig. 1: the eyes are slightly perceptible as small dots under the head scales. The coloration varies from light brown to black dorsally, while it's usually lighter ventrally. Fig. 2: I. braminus is a small snake, showing a total length ranging between $120 \mathrm{~mm}$ and $230 \mathrm{~mm}$. Here, the comparison with a coin of 5 cents. Fig. 3: the head shows rows of the typical whitish cephalic glands. The glands have been described as forming "a faint crenellated whitish marginal line" (Wallach, 2009). Figure 1d. The tail is very short and is characterized by a conical spine capping the terminal caudal vertebra.

must be carefully evaluated. Besides, considering that our observation involved a small island, where geographical isolation and the scarce dispersion can further influence the native species, the study of a possible future impact of $I$. braminus deserves deeper investigation. A careful control above all of gardening and careful instructions to gardeners and florists, can play a pivotal role in the primary prevention, avoiding and/or reducing new introductions.

\section{ACKNOWLEDGENENTS}

We thank you Mr. Simone De Santis (Ischia, Italy) for the photographic contribution and Mrs. Rosanna Magno (Ischia, Italy) for its courtesy and helpfulness.

\section{REFERENCES}

Bamford M. \& Prendergast K., 2017. A further record and observations on the flowerpot snake Indotyphlops braminus in suburban Perth. The Westerm Australian Naturalist, 30: 229-234.

Geniez P., 2018. Snakes of Europe, North Africa and the Middle East: A Photographic Guide. Princenton University Press, Princenton, 384 pp.

Kamosawa M. \& Ota H., 1996. Reproductive biology of the brahminy blind snake (Ramphotyphlops braminus) from the Ryukyu Archipelago. Journal of Herpetology, 30: 9-14.

Rato C., Silva-Rocha I., Gonzalez-Miras E., RodriguezLuque F., Farina B. \& Carretero M.A., 2015. A molecular assessment of European populations of Indotyphlops braminus (Daudin, 1803). Herpetozoa, 27: 179-182.

Wallach V., 2009. Ramphotyphlops braminus (Daudin): 
a synopsis of morphology, taxonomy, nomenclature and distribution (Serpentes: Typhlopidae). Hamadryad, 34: 34-61.
Zamora F.J., 2017. On the role of plant nurseries introducing Indotyphlops braminus (Daudin, 1803), in Spain. Herpetozoa, 30: 69-72. 